\title{
Indocyanine green-enhanced fluorescence to assess bowel perfusion during laparoscopic colorectal resection
}

\author{
Luigi Boni $^{1}$ - Giulia David ${ }^{1} \cdot$ Gianlorenzo Dionigi $^{1} \cdot$ Stefano Rausei $^{1}$ • \\ Elisa Cassinotti ${ }^{1} \cdot$ Abe Fingerhut $^{2,3}$
}

Received: 6 July 2015 / Accepted: 1 September 2015/Published online: 20 October 2015

(c) The Author(s) 2015. This article is published with open access at Springerlink.com

\begin{abstract}
Aims Anastomotic leakage after colorectal surgery is a severe complication. One possible cause of anastomotic leakage is insufficient vascular supply. The aim of this study was to evaluate the feasibility and the usefulness of intraoperative assessment of vascular anastomotic perfusion in colorectal surgery using indocyanine green (ICG)enhanced fluorescence.

Methods Between May 2013 and October 2014, all anastomosis and resection margins in colorectal surgery were investigated using fluorescence angiography (KARL STORZ GmbH \& Co. KG, Tuttlingen, Germany) intraoperatively to assess colonic perfusion prior to and after completion of the anastomosis, both in right and left colectomies. Results A total of 107 patients undergoing colorectal laparoscopic resections were enrolled: 40 right colectomies, 10 splenic flexure segmental resections, 35 left colectomies, and 22 anterior resections. In $90 \%$ of cases, the indication for surgery was cancer and high ligation of vessels was performed. Based on the fluorescence intensity, the surgical team judged the distal part of the proximal bowel to be anastomosed insufficiently perfused in $4 / 107$ patients (two anterior, one sigmoid and one segmental splenic flexure resections for cancer), and consequently,
\end{abstract}

Luigi Boni

luigi.boni@uninsubria.it

1 Minimally Invasive Surgery Research Center, Department of Surgical and Morphological Sciences, University of Insubria, 21100 Varese, Italy

2 Section for Surgical Research, Department of Surgery, Medical University of Graz, Graz, Austria

3 First Department of Surgery, Hippokration University Hospital, University of Athens, Athens, Greece further proximal "re-resection" up to a "fluorescent" portion was performed. None of these patients had a clinical leak. The overall morbidity rate was $30 \%$; one patient undergoing right colectomy had an anastomotic leakage, apparently unrelated to ischemia; there were no clinical evident anastomotic leakages in colorectal resections including all low anterior resections.

Conclusions ICG-enhanced fluorescent angiography provides useful intraoperative information about the vascular perfusion during colorectal surgery and may lead to change the site of resection and/or anastomosis, possibly affecting the anastomotic leak rate. Larger further randomized prospective trials are needed to validate this new technique.

Keywords ICG - Indocyanine green - Bowel perfusion · Anastomotic leaks · Colorectal resection . Fluorescence

Anastomotic leakage is one of the most dreaded postoperative complications in colorectal surgery. The reported leak rate ranges from 1 to $30 \%[1-3]$ and increases as the anastomosis is more distal [3]. The reported rate of patients with an anastomotic leak that requires surgical revision ranges from 10 to $35 \%[4,5]$ with a mortality rate ranging from 6 to $22 \%[1,6]$.

Although several factors have been identified as possible causes of anastomotic leakage (i.e., surgical techniques, patient risk factors, suture material or devices), the complete pathogenesis is still unclear [6,7].

Poor local tissue oxygenation secondary to inadequate anastomotic vascular perfusion seems to play a key role in the determination of anastomotic viability [8, 9]. Notwithstanding, to date, the most widely used "technique" to evaluate tissue perfusion is surgeon intraoperative visual judgment based on clinical findings, such as color, bleeding edges of resected margins, pulsation and 
temperature. However, at least two studies have suggested that the clinical judgment of the operating surgeon underestimated the risk of anastomotic leakage in colorectal surgery $[10,11]$.

Indocyanine green (ICG) is a sterile, anionic, watersoluble but relatively hydrophobic, tricarbocyanine molecule and, once injected into the vascular system, via the intravenous route, binds to plasma proteins. Based on the ability of ICG to become fluorescent when excited by nearinfrared light [12], real-time intraoperative organ perfusion evaluation with ICG has been used in several clinical applications [13] including plastic, gastrointestinal and transplant surgery [14-16], as well as bowel perfusion prior to or after colorectal anastomosis [17].

The aim of this study is to analyze our experience with ICG-enhanced fluorescence to evaluate the perfusion of the bowel during laparoscopic colorectal resection.

\section{Methods}

ICG-enhanced fluorescence was performed in all patients undergoing laparoscopic colorectal surgery between May 2013 and October 2014. The study was conducted according to the Declaration of Helsinki.

Patients with a history of adverse reaction to ICG and/or iodine, pregnant and/or lactating women were not included.

Preoperative risk factors including age, sex, American Society of Anesthesiologists (ASA) score, obesity, comorbidities, steroid therapy, preoperative radiation and preoperative transfusions were recorded.

Intraoperative ICG-enhanced fluorescence was used to assess colonic perfusion after intestinal resection, prior to and after completion of the anastomosis, both in right and left colectomies.

Recorded operative details included the site and level of the anastomosis, intracorporeal or extracorporeal anastomosis, vessel ligation, splenic flexure mobilization, use of drainage, intraoperative transfusions and diverting ileostomy.

The site of resection was selected by the surgeon before the ICG injection and marked with a clip (Fig. 1A).

Bowel transection, anastomosis and florescence angiography were performed intra-corporally for right colectomies, while in left colectomies, anterior resection fluorescence angiography and resection were performed outside the abdomen through a mini-laparotomy.

Twenty-five milligrams of ICG was diluted in $10 \mathrm{ml}$ of soluble water, and a bolus of $0.2 \mathrm{mg} / \mathrm{Kg}$ was injected intravenously by the anesthesiologist through a peripheral vein after the division of the mesentery and colon, but before anastomosis.
The timing before ICG visualization and intravenous injection was recorded.

Due to the lack of any objective technique to measure the intensity of the fluorescence, perfusion of the bowel was subjectively assessed by the surgical team (main surgeon, main assistant, fellow in minimally surgeon and the assisting resident) who also indicated the perfusion level as "adequate" (meaning uniform to that of proximal colon) or "insufficient." If poor perfusion was demonstrated, we waited further $180 \mathrm{~s}$ prior to re-resect the bowel.

Perfusion images were recorded and assessed in real time (Fig. 1).

Any information or change in timing and/or quantity of injection as well as any change in the transection line after ICG-enhanced fluorescence injection was recorded.

After completion of the anastomosis, another bolus of $0.2 \mathrm{mg} / \mathrm{Kg}$ of ICG was injected and a second evaluation of perfusion was made.

An air-leak test was performed after completion of anastomosis at the end of the procedure. The integrity of doughnuts in left hemicolectomies was checked after completion of the anastomosis.

Severity of complications was evaluated according to the Clavien/Dindo classification [18].

\section{Laparoscopic equipment}

The laparoscopic SPIES system (KARL STORZ GmbH \& Co. KG, Tuttlingen, Germany) and high-end full highdefinition camera system (IMAGE 1 SPIESTM, KARL STORZ) were used in all cases.

We used a xenon light source (D-LIGHT P SCB, KARL STORZ) providing both visible and NIR excitation light. Switching from standard light to NIR was controlled by the surgeon by means of a pedal. ICG fluorescence images appeared blue under NIR excitation, while all other tissues appeared black.

\section{Results}

During the study period, ICG-enhanced fluorescence was used to assess bowel perfusion in 107 patients (mean age $69 \pm 12$ years, 47 females and 60 males) undergoing right colectomy $(n=40)$, splenic flexure segmental resections $(n=10)$, left colectomy $(n=35)$ and anterior resection $(n=22)$ (Tables 1,2$)$. Splenic flexure segmental resections are intended for large adenoma not suitable for endoscopic resection or small cancer. In these cases, the inferior mesenteric artery was fully dissected, and the left colic artery ligated at its origin. Similarly, the middle colic artery was dissected, and the left branch ligated at its 
Fig. 1 Intraoperative view of the descending colon after division of the mesentery: Surgical clip is placed at the point of planned transection (A view with standard light, B view with NIR light showing good perfusion)
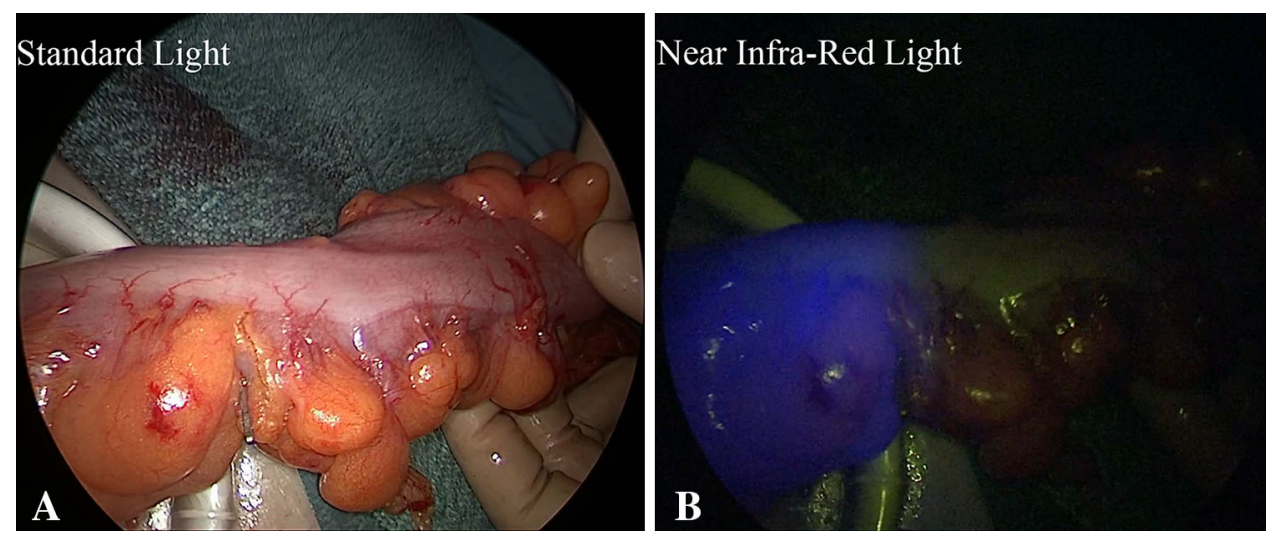

Table 1 Patient characteristics

\begin{tabular}{ll}
\hline Number & 107 \\
Gender (M/F) & $60 / 47$ \\
Average age (years) \pm standard deviation & $69( \pm 12)$ \\
Indication for surgery & \\
Colorectal cancer & 97 \\
Colorectal adenoma & 4 \\
Diverticular disease & 4 \\
Crohn's disease & 2 \\
\hline
\end{tabular}

Table 2 Patient comorbidities $(n=107)$

origin. This is routinely done in our practice since no evidence of oncological benefits of extended resection is reported in the literature.

Resection for malignancy was the main indication for surgery (97/107 cases, $90.6 \%)$, and in those cases, a "medial-to-lateral" approach with high ligation of the main feeding vessels was used. Stapled anastomosis was intracorporeal in $90 / 107$ cases $(84.1 \%)$ and extracorporeal in the other 17 patients $(15.8 \%)$. Five patients $(4.7 \%)$ had undergone preoperative endoscopic stent placement for obstructed malignant cancer as a bridge to surgery.

There were no intraoperative adverse events or conversion to open surgery. Protective ileostomy was carried
Table 3 Perioperative data $(n=107)$

\begin{tabular}{lll}
\hline Operative data & $N$ & $\%$ \\
\hline Right colectomies & 40 & 37 \\
Splenic flexure resections & 10 & 9 \\
Left colectomies & 35 & 33 \\
Anterior resection & 22 & 21 \\
$<5 \mathrm{~cm}$ & 7 & 32 \\
$5-8 \mathrm{~cm}$ & 8 & 36 \\
$>8 \mathrm{~cm}$ & 7 & 32 \\
Ostomy & 17 & 16 \\
High ligation vessels* & 97 & 91 \\
Low ligation vessels & 10 & 9 \\
ICG fluorescence imaging detection & 107 & 100 \\
Change in point of transection & 4 & 3.73 \\
Revision of anastomosis & 0 & 0 \\
Operative time (min) (range) & 130 & $(45-180)$ \\
\hline
\end{tabular}

* High ligation: ligation of the inferior mesenteric artery proximal to the left colic artery in left colectomies and anterior resections/ligation of collateral branches flush to the superior mesenteric vessels in right colectomies

out in 17 patients $(77.3 \%)$ undergoing low anterior resection. (Table 3 ).

There were no side effects related to the injection of ICG.

ICG-enhanced fluorescence was detected in $100 \%$ of the cases, and the mean time from IV ICG injection and fluorescence occurred was an average of $57 \pm 26 \mathrm{~s}$ after injection.

No changes in surgical plan were decided before fluorescence angiography. In all cases, the surgical team judged the perfusion of the colon adequate on standard white light, according to the color of the bowel, and no visible sign of ischemia was evident at visual inspection.

Based on the fluorescence intensity recorded under NIR light, after injection of ICG, the distal part of the proximal 
bowel to be anastomosed was judged to be insufficiently perfused and the surgical team opted for further proximal "re-resection" up to an "adequate" fluorescent part in 4/107 patients (3.7\%) (two anterior, one sigmoid and one segmental splenic flexure resections for cancer) (Fig. 2).

The complete lack of fluorescence (3/4 cases) or the macroscopically less fluorescence in comparison with the proximal portion of bowel ( $1 / 4$ case) was used as criteria to detect the poor perfusion. None of these patients had clinical anastomotic leaks.

In two of these patients, the change in surgical plan entailed further splenic flexure mobilization.

The postoperative course was uneventful in $74 / 107$ (69.1\%) patients, while the remaining $33(30.8 \%)$ had one or more postoperative complications described in Table 4 .

One patient underwent re-operation for anastomotic leakage after right colectomy due to incomplete closure of the enterotomy used for stapler introduction. We reported no clinical evident anastomotic leakage in any of the left sided colectomies, including all the low anterior resections.

Reversal of ostomy was performed in 20/22 patients, the anastomotic evaluation prior to reversal was always made either by means of rigid endoscopy (17/20 patients) or gastrografin enema (3/20), and no sign of leaks or stenosis was reported.

\section{Discussion}

Anastomotic breakdown can be due to mechanically faulty (technical or firing/cutting mishaps) or perfusion problems. The former can be sought intraoperatively by testing for air-tightness with air or methylene blue, or intraoperative endoscopy [19], and the second requires other techniques.

Intraoperative assessment of intestinal perfusion and viability usually relies on subjective judgment based on visual inspection. However, it has been shown that surgeon's subjective evaluation and prediction of anastomotic leakage are poor [11]. In the study by Karliczek et al. [10], surgeons were asked to estimate the risk of anastomotic leakage in 191 patients undergoing colorectal resection with anastomosis; the risk was compared to the actual occurrence of anastomotic leakage postoperatively (26/ $191=13.6 \%)$. The predictive value of surgeons' opinion was low; the $14 \%$ a priori risk of anastomotic leakage resulted in a low $(11 \%)$ posttest odds of correct prediction of anastomotic leakage.

Intraoperative perfusion assessment techniques such as transabdominal Doppler ultrasound [20], transabdominal laser Doppler flowmetry [21] and oxygen spectroscopy [22] have not been widely accepted because such techniques cannot be easily applied in routine clinical practice or have not proven reliable. Vignali et al. [23] measured the microperfusion in 55 patients undergoing colorectal anastomosis with Doppler flowmetry; they changed the anastomotic site when the oxygen content was $<50 \%$ from

Table 4 Postoperative complications $(n=107)$

\begin{tabular}{lcl}
\hline Postoperative morbidity & $N$ & $\%$ \\
\hline Ileus & 6 & 5.6 \\
Postoperative anemia requiring transfusions & 4 & 3.7 \\
Fever & 3 & 2.8 \\
Pulmonary complications & 3 & 2.8 \\
Wound infections & 3 & 2.8 \\
Urinary tract infections & 2 & 1.8 \\
Incisional hernia & 2 & 1.8 \\
Urinary retention & 2 & 1.8 \\
Rectal bleeding & 2 & 1.8 \\
Postoperative leak & 1 & 0.9 \\
Others & 5 & 4.6 \\
Severity of complication [21] & & \\
$\quad$ Mild (Clavien Dindo 1) & 23 & 21.4 \\
Moderate (Clavien Dindo 2) & 9 & 8.4 \\
Severe (Clavien Dindo 3-5) & 1 & 0.9 \\
Re-operation & 1 & 0.9 \\
Mortality & 0 & 0 \\
\hline
\end{tabular}

Fig. 2 Intraoperative view of the descending colon in a case of hypoperfusion at the point of planned transection (arrows)
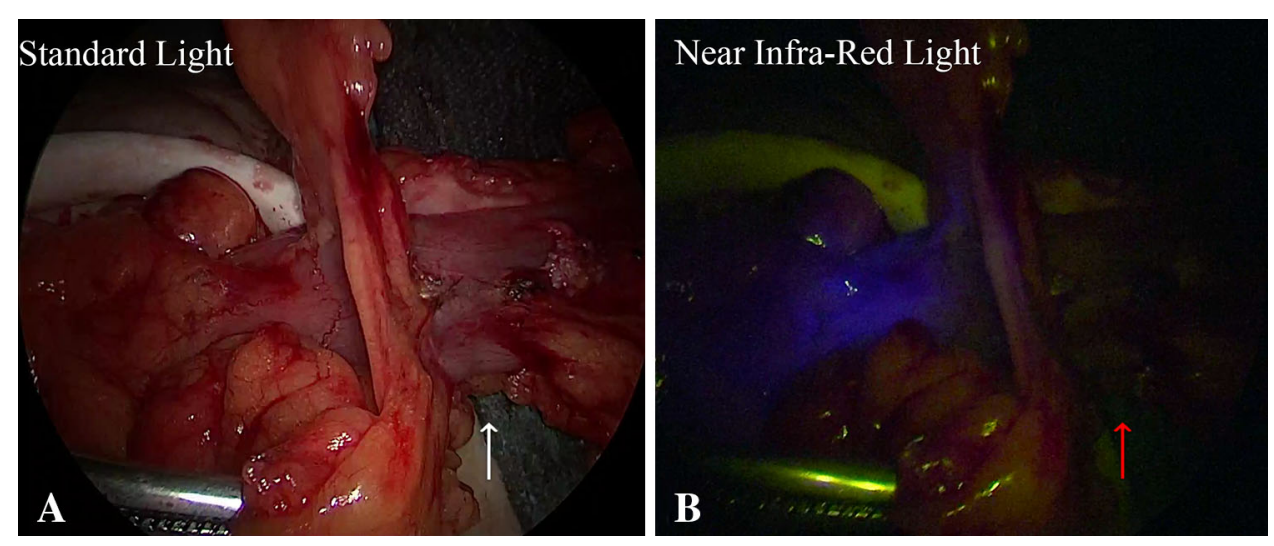
baseline. Notwithstanding, they still observed a $14.5 \%$ leakage rate.

Indocyanine green angiography is a more recent development in colorectal surgery. Kudszus et al. [24] demonstrated a reduction in risk of surgical revision of $60 \%$ (7.5-3.5\%) using fluorescence angiography in a casematched retrospective study. These data have been confirmed by Jafari et al. [25] during robotic-assisted laparoscopic rectal surgery.

A multicenter prospective trial on fluorescence angiography in colorectal surgery in 147 patients who underwent laparoscopic or robotic left colectomy or anterior resection showed that ICG angiography led to change the surgical plan in eleven patients (7.9\%) [18]; their overall anastomotic leak rate was low (1.4\%, two patients) compared to the literature [26], perhaps because none of the 11 patients with problematic vascular supply detected by this method had an anastomotic leakage after revision.

A recent retrospective case-matched study by Kin et al. [27] on colorectal resection demonstrated that once fluorescence angiography was performed, surgeons decided to change the proximal resection margin in $8 / 173$ patients $(4.6 \%)$ but this was not correlated with a significant reduction in the leak rate once compared to the matched group where fluorescence angiography was not performed. Nevertheless, the authors acknowledged several limitations of their study including the retrospective nature, the different period of time where the two groups were compared, the small sample size and the presence of potential confounders between the two groups.

Among the different risk factors for anastomotic leakage, adequate perfusion is a well-recognized prerequisite for complete healing of anastomosis [23, 27, 28].

Adequate vascular supply of the left colon depends on the patency of the inferior mesenteric artery, the left colic artery but also relies on patency of the middle colic artery and the marginal Drumond and eventually Riolan arcades $[29,30]$. Anatomic variations are frequent, and aberrations such as absence of the middle colic artery or inadequate vascularization of the splenic flexure are frequent (up to $25 \%$ ) [31-33]. High ligation of the inferior mesenteric artery has been documented as a risk factor for anastomotic leakage [34].

The concept of high ligation of the vessels to achieve optimal oncological results [29] suppresses the vascular supply from the left colic artery, and vascularization of the proximal colon is dependent on marginal vessels running off the middle colic artery. With the progressive increase in the aging population undergoing surgery for colorectal disease, radiation, vascular disease can also be a factor of insufficient vascular supply, even in the case of low ligation of the inferior mesenteric artery.
In our study, $92 \%$ patients had high ligation of the inferior mesenteric artery (53 of 57 left colectomies) and $54 \%$ had splenic flexure mobilization (31/57). In the study by Hellan et al. [35], all patients undergoing resection for malignant disease had high ligation. The number of patients undergoing splenic flexure was not stated. Fluorescence evaluation, in contrast to the surgeons' clinical assessment, led to a more proximal level of division in $16 / 40(40 \%)$ of patients. Two leaks occurred in spite of change in anastomotic site in their series [35]. Possible explanations may be the non-standardization of injection and reinjection schedules. Moreover, the authors did not test the anastomoses for air-tightness, not give any details on the vascularization after changing the site of resection, but it is also possible that they were not related to a vascular problem, or there was an undetected discontinuation of the marginal artery.

Patients who have undergone radiation therapy [36] and aortic aneurysm repair [37] might also be at high risk of precarious vascular supply to the splenic flexure [38]. Another risk factor for AL is patients undergoing ultra-low anastomosis. None of the patients undergoing anastomosis $<5 \mathrm{~cm}$ from the anal verge in our study sustained an AL. This is in accordance with the outcomes of the studies by Kudszus et al. [24] and Jafari et al. [25], where the proportion of patients with low rectal anastomosis and preoperative radiation therapy was high.

Images were obtained in $100 \%$ of our patients, similar to what was obtained for 150 graft perfusions in esophageal surgery reported recently by Zehetner et al. [16] and Hellan et al. [35] for colorectal surgery, but slightly superior to $98.6 \%$ in the PILLAR II study [17].

The technique of intraoperative evaluation still has several unknowns or drawbacks.

One unknown is the optimal dose and timing of ICG injection before assessment. While the ideal time lag between injection and visualization of bile and bile ducts is under scrutiny [38], the wash-out time of the vascular system is much quicker and the precise injection schedule remains to be found. Hellan et al. [35] found that while the microperfusion was usually evident after a few seconds, a bolus injection of ICG was needed to complete the assessment in $7 / 40(17.5 \%)$ of patients. The effect of repeated injections of ICG is not known and has not been investigated [39].

Another drawback is that there is still no strict analytic measure to objectively quantify the signal intensity, and the evaluation of images still depends on the surgeon's judgment. One recent experimental study has targeted this aspect [40] assessing the perfusion of porcine colonic segments after creating a survival ischemic model by ligation and then evaluating the intensity of the fluorescent 
image. However, this study has several shortcomings. The model of evaluation was based on time to peak intensity. The authors do not provide the rationale for the binary character of good or bad perfusion (over $50 \%$ or $<50 \%$ rise in time to peak intensity) on which their model was based. Whether this variable has any bearing on the adequateness of vascular supply to the intestine to prevent anastomotic leakage remains to be shown.

This leads to another unknown factor, which is that the precise blood flow rate needed to ensure satisfactory healing of the intestinal tissue remains unclear at the present time. At least two studies [21, 22] focused on the blood supply assessed using Doppler flowmetry, but although both demonstrated reduced blood flow after resection, it is not clear what is the minimal blood flow to avoid anastomotic leakage [7].

Other variables that have to be considered are the variations in intensity relative to respiratory movements, which measured the intensity at the end of a 20-s apnea period, the distance between the camera and the intestines, the influence of the speed (number of frames/s) of the camera, the quality of the cable for transmission of the light, the body mass index (or any other quantitative measurement of obesity) on the intensity of the image, the amount of ambient white light when the measurement is made outside the abdomen. It also seems important to highlight that perfusion should be tested with the distal segment of intestines (colon) in its definitive position after anastomosis (to be sure that the perfusion does not change due to any tension, or anatomic factor occurring after division and anastomosis.

Notwithstanding, and despite the limitations due to a small-size study, ICG-enhanced fluorescence, as used herein, seems to be safe, reproducible, simple and costeffective to assess colonic and anastomotic perfusion.

\section{Conclusions}

In our experience, injection of a few milliliters of ICG provides real-time evidence of perfusion of the bowel prior to proximal transection, after division of the mesentery and before the completion of the anastomosis in its definitive anatomic position. If our results will be confirmed by larger prospective studies, intraoperative ICG fluorescent angiography, as described herein, might offer the possibility to lower the rate of anastomotic leaks and the resulting morbidity and mortality rate.

\section{Compliance with ethical standards}

Disclosures Luigi Boni, Giulia David, Gianlorenzo Dionigi, Stefano Rausei, Elisa Cassinotti and Abe Fingerhut have nothing to disclose.
Open Access This article is distributed under the terms of the Creative Commons Attribution 4.0 International License (http://crea tivecommons.org/licenses/by/4.0/), which permits unrestricted use, distribution, and reproduction in any medium, provided you give appropriate credit to the original author(s) and the source, provide a link to the Creative Commons license, and indicate if changes were made.

\section{References}

1. Buchs NC, Gervaz P, Secic M, Bucher P, Mugnier-Konrad B, Morel P (2008) Incidence, consequences, and risk factors for anastomotic dehiscence after colorectal surgery: a prospective monocentric study. Int J Colorectal Dis 23(3):265-270

2. Mirnezami A, Mirnezami R, Chandrakumaran K, Sasapu K, Sagar P, Finan P (2011) Increased local recurrence and reduced survival from colorectal cancer following anastomotic leak: systematic review and meta-analysis. Ann Surg 253(5):890-899

3. Park JS, Choi GS, Kim SH, Kim HR, Kim NK, Lee KY, Kang SB, Kim JY, Lee KY, Kim BC, Bae BN, Son GM, Lee SI, Kang H (2013) Multicenter analysis of risk factors for anastomotic leakage after laparoscopic rectal cancer excision: the Korean laparoscopic colorectal surgery study group. Ann Surg 257(4):665-671

4. Alves A, Panis Y, Pocard M, Regimbeau JM, Valleur P (1999) Management of anastomotic leakage after nondiverted large bowel resection. J Am Coll Surg 189(6):554-559

5. Nesbakken A, Nygaard K, Westerheim O, Lunde OC, Mala T (2002) Audit of intraoperative and early postoperative complications after introduction of mesorectal excision for rectal cancer. Eur J Surg 168(4):229-235

6. Al Asari S, Cho MS, Kim NK. (2015) Safe anastomosis in laparoscopic and robotic low anterior resection for rectal cancer: a narrative review and outcomes study from an expert tertiary center. Eur J Surg Oncol 41(2):175-185

7. Shogan BD, Carlisle EM, Alverdy JC, Umanskiy K (2013) Do we really know why colorectal anastomoses leak? J Gastrointest Surg. 17(9):1698-1707

8. Frasson M, Flor-Lorente B, Ramos Rodríguez JL, Granero-Castro P, Hervás D, Alvarez Rico MA, Brao MJ, Sánchez González JM, Garcia-Granero E; ANACO Study Group; ANACO Study Group (2015) Risk factors for anastomotic leak after colon resection for cancer: multivariate analysis and nomogram from a multicentric, prospective, national study with 3193 patients. Ann Surg 262(2):321-330

9. Kingham TP, Pachter HL (2009) Colonic anastomotic leak: risk factors, diagnosis, and treatment. J Am Coll Surg 208(2):269-278

10. Karliczek A, Harlaar NJ, Zeebregts CJ, Wiggers T, Baas PC, Van Dam GM (2009) Surgeons lack predictive accuracy for anastomotic leakage in gastrointestinal surgery. Int $\mathrm{J}$ Colorectal Dis 24(5):569-576

11. Markus PM, Martell J, Leister I, Horstmann O, Brinker J, Becker H (2005) Predicting postoperative morbidity by clinical assessment. Br J Surg 92:101-106

12. Luo S, Zhang E, Su Y, Cheng T, Shi C (2011) A review of NIR dyes in cancer targeting and imaging. Biomaterials 32:7127-7138

13. Boni L, David G, Mangano A, Dionigi G, Rausei S, Spampatti S, Cassinotti E, Fingerhut A (2014) Clinical applications of indocyanine green (ICG) enhanced fluorescence in laparoscopic surgery. Surg Endosc. doi:10.1007/s00464-014-3895-x

14. Liu DZ, Mathes DW, Zenn MR, Neligan PC (2014) The application of indocyanine green fluorescence angiography in plastic surgery. J Reconstr Microsurg 27(6):355-364

15. Arichi N, Mitsui Y, Ogawa K, Nagami T, Nakamura S, Hiraoka T, Yasumoto H, Shiina H (2014) Intraoperative fluorescence 
vascular Imaging using indocyanine green for assessment of transplanted kidney perfusion. Transplant. 46:342-345

16. Zehetner J, DeMeester SR, Alicuben ET, Oh DS, Lipham JC, Hagen JA, DeMeester TR (2014) Intraoperative assessment of perfusion of the gastric graft and correlation with anastomotic leaks after esophagectomy. Ann Surg. doi:10.1097/SLA.0000000 000000811

17. Jafari MD, Wexner SD, Martz JE, McLemore EC, Margolin DA, Sherwinter DA, Lee SW, Senagore AJ, Phelan MJ, Stamos MJ (2015) Perfusion assessment in laparoscopic left-sided/anterior resection (PILLAR II): a multi-institutional study. J Am Coll Surg 220(1):82-92.e1

18. Clavien PA, Barkun J, de Oliveira ML, Vauthey JN, Dindo D, Schulick RD, de Santibanes Pekolj J, Slankamenac K, Bassi C, Graf R, Vonlanthen R, Padbury R, Cameron J, Makuchi M (2009) The Clavien-Dindo classification of surgical complications fiveyear experience. Ann Surg 250:187-196

19. Daams F, Wu Z, Lahaye MJ, Jeekel J, Lange JF (2014) Prediction and diagnosis of colorectal anastomotic leakage: a systematic review of literature. World J Gastrointest Surg 6(2):14-26

20. Ambrosetti P, Robert J, Mathey P, Rohner A (1994) Left-sided colon and colorectal anastomoses: doppler ultrasound as an aid to assess bowel vascularization. A prospective evaluation of 200 consecutive elective cases. Int J Colorectal Dis 9(4):211-214

21. Boyle NH, Manifold D, Jordan MH, Mason RC (2000) Intraoperative assessment of colonic perfusion using scanning laser Doppler flowmetry during colonic resection. J Am Coll Surg 191(5):504-510

22. Karliczek A, Benaron DA, Baas PC, Zeebregts CJ, Wiggers T, van Dam GM (2010) Intraoperative assessment of microperfusion with visible light spectroscopy for prediction of anastomotic leakage in colorectal anastomoses. Colorectal Dis 12(10):1018-1025

23. Vignali A, Gianotti L, Braga M, Radaelli G, Malvezzi L, Di Carlo V (2000) Altered microperfusion at the rectal stump is predictive for rectal anastomotic leak. Dis Colon Rectum 43(1):76-82

24. Kudszus S, Roesel C, Schachtrupp A, Höer JJ (2010) Intraoperative laser fluorescence angiography in colorectal surgery: a noninvasive analysis to reduce the rate of anastomotic leakage. Langenbecks Arch Surg 395(8):1025-1030

25. Jafari MD, Lee KH, Halabi WJ, Mills SD, Carmichael JC, Stamos MJ, Pigazzi A (2013) The use of indocyanine green fluorescence to assess anastomotic perfusion during robotic assisted laparoscopic rectal surgery. Surg Endosc 27(8):3003-3008

26. Pigazzi A, Luca F, Patriti A, Valvo M, Ceccarelli G, Casciola L, Biffi R, Garcia-Aguilar J, Baek JH (2010) Multicentric study on robotic tumor-specific mesorectal excision for the treatment of rectal cancer. Ann Surg Oncol 17(6):1614-1620

27. Kin C, Vo H, Welton L, Welton M (2015) Equivocal effect of intraoperative fluorescence angiography on colorectal anastomotic leaks. Dis Colon Rectum 58(6):582-587
28. Sheridan WG, Lowndes RH, Young HL (1987) Tissue oxygen tension as a predictor of colonic anastomotic healing. Dis Colon Rectum 30:867

29. Al-Asari SF, Lim D, Min BS, Kim NK (2013) The relation between inferior mesenteric vein ligation and collateral vessels to splenic flexure: anatomical landmarks, technical precautions and clinical significance. Yonsei Med J 54(6):1484-1490

30. Titu LV, Tweedle E, Rooney PS (2008) High tie of the inferior mesenteric artery in curative surgery for left colonic and rectal cancers: a systematic review. Dig Surg. 25(2):148-157

31. Golligher JC (1954) The adequacy of the marginal blood supply to the left colon after high ligation of the inferior mesenteric artery during excision of the rectum. Br J Surg 41:351-353

32. Griffiths JD (1956) Surgical anatomy of the blood supply of the distal colon. Ann R Coll Surg Engl 19:241-256

33. Sakorafas GH, Zouros E, Peros G (2006) Applied vascular anatomy of the colon and rectum: clinical implications for the surgical oncologist. Surg Oncol 15(4):243-255

34. Trencheva K, Morrissey KP, Wells M, Mancuso CA, Lee SW, Sonoda T, Michelassi F, Charlson ME, Milsom JW (2013) Identifying important predictors for anastomotic leak after colon and rectal resection prospective study on 616 patients. Ann Surg 257:108-113

35. Hellan M, Spinoglio G, Pigazzi A, Lagares-Garcia JA (2014) The influence of fluorescence imaging on the location of bowel transection during robotic left-sided colorectal surgery. Surg Endosc 28(5):1695-1702

36. Alves A, Panis Y, Trancart D, Regimbeau JM, Pocard M, Valleur $P$ (2002) Factors associated with clinically significant anastomotic leakage after large bowel resection: multivariate analysis of 707 patients. World J Surg 26(4):499-502

37. Leather RP, Shah DM, Kaufman JL (1989) Comparative analysis of retroperitoneal and transperitoneal aortic replacement for aneurysm. Surg Gynecol Obstet 168:38-41

38. Verbeek FP, Schaafsma BE, Tummers QR, van der Vorst JR, van der Made WJ, Baeten CI, Bonsing BA, Frangioni JV, van de Velde CJ, Vahrmeijer AL, Swijnenburg RJ (2014) Optimization of near-infrared fluorescence cholangiography for open and laparoscopic surgery. Surg Endosc 28:1076-1082

39. Diana M, Halvax P, Dallemagne B, Nagao Y, Diemunsch P, Charles AL, Agnus V, Soler L, Demartines N, Lindner V, Geny B, Marescaux J (2014) Real-time navigation by fluorescencebased enhanced reality for precise estimation of future anastomotic site in digestive surgery. Surg Endosc 28:3108-3118

40. Diana M, Agnus V, Halvax P, Liu YY, Dallemagne B, Schlagowski AI, Geny B, Diemunsch P, Lindner V, Marescaux J (2015) Intraoperative fluorescence-based enhanced reality laparoscopic real-time imaging to assess bowel perfusion at the anastomotic site in an experimental model. Br J Surg 102(2): 169-176 